\title{
Research on Evaluation and Improvement of Perceived Value of Study Tour for Primary and Middle School Students
}

\author{
Li Li*1 \\ ${ }^{1}$ Department of Tourism and Service Management Chongqing University of Education Chongqing, China
}

\begin{abstract}
The student perceived value is an important criterion for evaluating the success of study tour. Firstly, the paper reviews domestic and foreign literature to define the concept and connotation of perceived value of study tour for primary and middle school students. Secondly, the paper summarizes the measurement scale of perceived value of study tour, and constructs a conceptual model. Then, it conducts questionnaire survey of 260 primary and middle school students in Chongqing, and makes statistical analysis on the survey data. The results show that, primary and middle school student perceived value of study tour in Chongqing is at the upper-middle level, but there is much room for improvement in ability value and emotional value. Finally, from two aspects, the paper proposes some countermeasure for improving the perceived value of study tour for primary and middle school students in Chongqing.
\end{abstract}

\section{INTRODUCTION}

Study tour has a long history of development in China, which can be traced back to $497 \mathrm{BC}$ when Confucius led his disciples to study in the surrounding countries. Since the beginning of the 21 st century, with the popularization of the concept of quality education, study tour has been favored by parents, schools and students. The government has also given greater attention and support to study tour. In 2013, the State Council issued the "Outline of National Tourism and Recreation (2013-2020)", proposing to "gradually promote study tour of primary and middle school students". In 2014, the State Council's Document No. 31 proposed to establish a study tour system based on the connotation of nostalgia education at different learning stages for the first time. In 2016, 11 Chinese ministries issued the doucument "Opinions on Promoting Study Tour for Primary and Middle School Students", which took study tour as a compulsory course for primary and middle school students. This marked a new development stage of study tour in China.

\section{LITERATURE REVIEW}

Study tour has been developed in developed countries such as the United States, Europe, Japan, and South Korea for a long time. It is called "educational tourism", and it's an important part of their youth education growth. Foreign scholars generally considered that education tourism was a form of group learning practice, which helped students to experience the society, learn natural and cultural knowledge, and improve cross-cultural understanding.
Representative scholars include Gunay Aliyeva, Samah AA, Ritchie BW, etc.

The research on study tour in China has gradually deepened with the national policies. It started in 2013 and has developed rapidly after 2016. Since study tour has two functions of "study" and "tour", the current research on study tour is mainly concentrated in the tourism perspective and education perspective. In the tourism perspective, scholars made research about industrial development, resource development, and tourist satisfaction relying on the theories such as economics, marketing, and consumer behavior. For example, Scholars such as Du Liqing, Zhao Bi, Zhao Yichen, Qiu Yue, Wang Lili, etc. respectively researched study tour products design in Zhejiang Jinhua, Hubei province, Anhui province, Jiangsu province. In the education perspective, scholars made research about the educational significance, instructional design, and curriculum model of study tour relying on the theory of pedagogy. Through optimization of study tour course, they hoped that study tour can improve students' abilities such as active exploration, communication, cooperation, practical operation, innovation and creativity. Representative scholars include Liu Jing, Tao Yimin, Zheng Jinrong, Shen Hongyan, etc.

In summary, although domestic research on study tour in primary and middle school has made great progress, the research perspective is mostly from the school education or tourism development to discuss how to optimize study tour project. It is less from the students perspective to research their perception. Research methods are mostly qualitative and lack quantitative methods. Although some scholars have paid attention to the perceived value of students, they are mostly concentrated on college students (representative scholars 
include Zhou Can, Pu Zhen, Wu Xiaoxia). They pay less attention to the perceived value of study travel for primary and middle school students. This may be related to their younger age, because it is not convenient for market research.

\section{Conceptual Model of the Perceived VALUE OF STUDY TOUR}

Zeithaml [1] was the first scholar to propose the concept of Customer Perceived Value (CPV). She defined customer perceived value from the perspective of customer psychology. Customer perceived value is overall utility evaluation of the product or service after measuring its benefits and costs. From the market perspective, the customers of study tour are students. Therefore, the perceived value of study tour is the overall utility evaluation of study tour from the perspective of students. The perceived value of study tour is a complex multidimensional variable. Firstly, the conceptual model of the perceived value of study tour should be constructed. Academic research on the effectiveness of study tour has become more abundant. Scholars have divided the constituent dimensions of study tour from different theoretical perspectives and classification standards. Therefore, the perceived value of study tour has not yet reached a unified understanding. Combining the research results of domestic and foreign scholars, based on interviews and surveys with primary and middle school students who have participated in study tour, this paper proposes that primary and middle school students' perceived value of study tour includes four constituent dimensions, including knowledge value, ability value, physical value, and emotional value (Table 1).

Table 1. Perceived Value of Study tour for Primary and MidDle SchoOl STUDENTS

\begin{tabular}{|c|c|c|}
\hline Dimension & Definition & Literature support \\
\hline $\begin{array}{c}\text { knowledge } \\
\text { value }\end{array}$ & $\begin{array}{c}\text { the utility of knowledge } \\
\text { through study tour }\end{array}$ & $\begin{array}{c}\text { representative scholars } \\
\text { include Yi Xinfa [2], Chen } \\
\text { Zhuqing [3] }\end{array}$ \\
\hline $\begin{array}{c}\text { ability } \\
\text { value }\end{array}$ & $\begin{array}{c}\text { the utility of ability } \\
\text { through study tour } \\
\text { physical } \\
\text { value }\end{array}$ & $\begin{array}{c}\text { the utility of physical } \\
\text { through study tour } \\
\text { include Li Donghe [4], } \\
\text { Zhong Linfeng [5] }\end{array}$ \\
\hline $\begin{array}{c}\text { emotional } \\
\text { value }\end{array}$ & $\begin{array}{c}\text { representative scholars } \\
\text { include Tao Yimin [6], } \\
\text { Yin Shidong [7] }\end{array}$ \\
\hline \multicolumn{2}{|c|}{ through study tour } & $\begin{array}{c}\text { representative scholars } \\
\text { include Wu Tao [8], Yang } \\
\text { Fei [9], Xu Mingbo [10] }\end{array}$ \\
\hline
\end{tabular}

\section{EMPIRICAL RESEARCH}

\subsection{Data Collection}

The respondents of this research are primary and middle school students in some schools in Chongqing, and the survey method is questionnaire. Since this research focuses on students' true perceived value, considering that primary school students in grades 1-3 have some difficulty in understanding and filling out the questionnaire, so the respondents are above grade 4. From March to June 2019, we distribute and collect the questionnaires mainly through teachers in primary and middle schools. 345 questionnaires were distributed and 309 questionnaires were returned in this survey. The questionnaire recovery rate was $89.5 \%$. After screening the questionnaires, 49 questionnaires were eliminated due to incompletely filled and low authenticity. Finally, a total of 260 valid questionnaires were obtained, and the effective questionnaire rate was $84.1 \%$. In this study, the method of processing questionnaire data mainly uses factor analysis. For factor analysis, the number of questionnaires should be 5 times the number of scale questions (Stevens [11]). The questionnaire of this research has 16 scale questions, so the minimum number of questionnaires is 80 . The number of valid questionnaires in this research was 260, so the questionnaire is suitable for factor analysis. The basic information of the survey sample is shown in Table 2.

TABLE 2 THE BASIC INFORMATION OF THE SURVEY SAMPLE $(\mathrm{N}=260)$

\begin{tabular}{|c|c|c|c|}
\hline Variable & Category & Quantity & Percentage (\%) \\
\hline \multirow{2}{*}{ gender } & male & 129 & 49.6 \\
\cline { 2 - 4 } & female & 131 & 50.4 \\
\hline \multirow{3}{*}{ grade } & $4-6$ & 160 & 61.5 \\
\cline { 2 - 4 } & 7 & 61 & 23.5 \\
\cline { 2 - 4 } & 8 & 39 & 15 \\
\hline
\end{tabular}

\subsection{Data Analysis Results}

4.2.1 Reliability and validity test: Using SPSS19.0 statistical software, this paper makes factor analysis. The result shows that: The KMO test of perceived value scale is $0.919>0.8$, and the Bartlett sphericity test $\mathrm{p}$ value is 0.000 , which indicates that the factor analysis method is suitable. The result of factor analysis shows that, the scale of primary and middle school students' perceived value of study tour can extract four factors. The loading value of each factor of is above 0.60 , and the interpretation rate of the overall variance reaches $74.163 \%$. The above results indicate that the construction validity of perceived value scale is good. Using SPSS19.0 software to make reliability analysis, the results show that Cronbach'a is $0.943>0.80$, which indicates that the reliability of perceived value scale is high, and the internal consistent reliability meets the requirements.

4.2.2 Factor analysis: This paper makes factor analysis on perceived value scale of primary and middle school students' study tour. It uses principal component analysis to extract factors, and use orthogonal variance maximum method to rotate factors, and output the rotated factor loading matrix. Factor extraction standard follows the Kaiser criterion, that is, select characteristic values Factors greater than 1. Kaiser, Wu Minglong, Qiu Haozheng and others scholars believe that factor loading above 0.45 is better. In this paper, it chooses the factor loading is above 0.45 . The result of factor analysis is shown in Table 3 . The 16 items of the perceived value scale of study tour for primary and middle school students can extract 4 factors, namely knowledge value (PV1-PV4), 
ability value (PV5-PV10), physical value (PV11-PV13), and emotional value (PV14-PV16).

TABLE 3 THE RESULT OF FACTOR ANALYSIS OF THE PERCEIVED VALUE SCALE OF STUDY TOUR FOR PRIMARY AND MIDDLE SCHOOL STUDENTS $(\mathrm{N}=260)$

\begin{tabular}{|c|c|c|c|c|}
\hline Variable & $\begin{array}{l}\text { Factor 1 } \\
\text { (knowledge } \\
\text { value) }\end{array}$ & $\begin{array}{c}\text { Factor } 2 \\
\text { (ability value) }\end{array}$ & $\begin{array}{c}\text { Factor } 3 \\
\text { (physical value) }\end{array}$ & $\begin{array}{l}\text { Factor } 4 \\
\text { (emotional } \\
\text { value) }\end{array}$ \\
\hline PV1 & .194 & .799 & .203 & .272 \\
\hline PV2 & .223 & .806 & .135 & .312 \\
\hline PV3 & .260 & .784 & .209 & .153 \\
\hline PV4 & .397 & .641 & .267 & .119 \\
\hline PV5 & .732 & .289 & .387 & .107 \\
\hline PV6 & .757 & .302 & .201 & .251 \\
\hline PV7 & .760 & .174 & .340 & .143 \\
\hline PV8 & .698 & .248 & .090 & .302 \\
\hline PV9 & .689 & .227 & .253 & .335 \\
\hline PV10 & .723 & .210 & .306 & .165 \\
\hline PV11 & .418 & .271 & .680 & .129 \\
\hline PV12 & .320 & .204 & .805 & .224 \\
\hline PV13 & .271 & .236 & .751 & .259 \\
\hline PV14 & .423 & .106 & .230 & .669 \\
\hline PV15 & .203 & .293 & .261 & .739 \\
\hline PV16 & .187 & .322 & .113 & .782 \\
\hline \multicolumn{5}{|c|}{$\begin{array}{l}\text { Factor extraction method: principal component analysis } \\
\text { Factor rotation method: orthogonal rotation method with Kaiser standardization } \\
\text { KMO }=0.919 \\
\text { Sig. }=0.000 \\
4 \text { factors cumulatively explained variance percentage }=74.163 \%\end{array}$} \\
\hline
\end{tabular}

4.2.3 Factor score evaluation: According to the results of factor analysis, this paper calculates knowledge value $(\mathrm{KV})$, ability value (AV), physical value (PV), and emotional value (EV) of the survey samples, and makes descriptive statistics analysis on the samples (Table 4).

TABLE 4 THE RESUlT OF DESCRIPTIVE STATISTICS ANALYSIS OF THE PERCEIVED VALUE SCALE OF STUDY TOUR FOR PRIMARY AND

\begin{tabular}{|c|c|c|c|c|c|c|}
\hline & $\mathbf{N}$ & Min & Max & Mean & $\begin{array}{c}\text { Std. } \\
\text { deviation }\end{array}$ & Variance \\
\hline $\begin{array}{c}\text { knowledge } \\
\text { value } \\
\text { (KV) }\end{array}$ & 260 & 1.00 & 5.00 & 4.1743 & 1.12472 & 1.265 \\
\hline $\begin{array}{c}\text { ability } \\
\text { value } \\
\text { (AV) }\end{array}$ & 260 & 1.00 & 5.00 & 3.4953 & 0.98590 & 0.972 \\
\hline $\begin{array}{c}\text { physical } \\
\text { value (PV) }\end{array}$ & 260 & 1.00 & 5.00 & 4.3631 & 0.82825 & 0.686 \\
\hline $\begin{array}{c}\text { emotional } \\
\text { value } \\
\text { (EV) }\end{array}$ & 260 & 1.00 & 5.00 & 3.6002 & 0.96229 & 0.926 \\
\hline
\end{tabular}

The data analysis results show that, primary and middle school students' perceived value of study tour in Chongqing is at the upper-middle level. The scores of each factor are physical value (4.3631), knowledge value (4.1743), emotional value (3.6002), and ability value (3.4953). From the comparison of the scores of the four factors, the physical value and knowledge value is at a good level, which reflects primary and middle school students can gain greater physical and knowledge harvest from study tour; while the emotional value and ability value are at a medium level, it reflects that primary and middle school students can gain less ability and emotional harvest from study tour.

\section{CONCLUSION AND DISCUSSION}

\subsection{Conclusion}

First, the perceived value of study tour for primary and middle school students is a complex multi-dimensional variable.

Theoretical research and empirical research results show that, the perceived value study tour for primary and middle school students includes four constituent dimensions, namely knowledge value (KV), ability value (AV), physical value (PV), emotional value (EV).

Second, primary and middle school students' perceived value of study tour in Chongqing is at the upper-middle level. Through a survey of 260 primary and middle school students, the scores of each factor are physical value (4.3631), knowledge value (4.1743), emotional value (3.6002), and ability value (3.4953). The physical value and knowledge value is at a good level, which indicates primary and middle school students can gain greater physical and knowledge utility from study tour; but there is still much room for improvement in the ability perceived value and emotional perceived value.

\subsection{Duscussion}

Based on the above research results, we should enhance perceived value of study tour from ability value and emotional value. The following measures are recommended. 
First, it should pay attention to four ability dimensions and enhance the ability value of study tour. According to State Council Document in September 2017, it proposed to focus on the cultivation of four key abilities of students: cognitive ability, cooperation ability, innovation ability, and professional ability. Therefore, the design of study tour should focus on these four abilities, and enhance ability perceived value. Cognitive ability focuses on students' understanding and learning ability of new things; cooperation ability focuses on interpersonal communication, cooperative inquiry, and collective awareness; innovation ability focuses on trying to explore, innovative creation, thinking extension; professional ability focuses on practical experience and professional cognition. At the same time, the study tout course should take activities as the main form, emphasizing students' personal experience, requiring students to actively participate.

Second, practice the core values of Chinese socialism and enhance the emotional value of study tour. It should integrate the core values of Chinese socialism into the study tour project, and promote students' love for the motherland's culture and traditional culture through cultural experience, folk experience, etc., and inspire their patriotism, hometown and collective feelings. Through study tour, it can enhance the students' national self-esteem, self-confidence, and pride, and inspire students to take responsibility.

\section{ACKNOWLEDGEMENT}

Humanities and social sciences research project of Chongqing Education Commission (20SKGH249), Graduate Education Teaching Reform Research Project of Chongqing Education Commission (yjg172012),

Chongqing Higher Education Science Research Project of Association of Higher Education of Chongqing (CQGJ17016A), Research platform of Chongqing University of Education (2017XJPT02).

\section{REFERENCES}

1. Zeithaml V A. Consumer perceptions of price,quality and value: a means-end model and synthesis of
evidence[J]. Journal of Marketing, 1988, 52(7), pp.32-35.

2. Yi Xinfa, Yi Xinfu. Study trips and cultivation of students' creativity [J]. The Education of Innovative Talents, 2017, (01), pp.49-55.

3. Chen Zhuqing. Explore Study Tour and Improve the Cognitive Ability of Geographical Regions [J]. Journal of Fujian Institute of Education, 2017 (3), pp.95-96.

4. Li Donghe, Wang Dandan, Zhu Lingling. The Relationship between Cognition, Satisfaction and Behavioral Intention of Students Groups towards Travel Study [J]. Journal of West Anhui University, 2016, 32(5), pp.103-110.

5. Zhong Linfeng, Tan Zhu. The value and system construction of study tour [J]. Journal of Teaching and Management, 2017(31), pp.36-39.

6. Tao Yimin. The gestation of students' core literacy in the study tour $[\mathrm{J}]$. Journal of Teaching and Management, 2017, (23), pp.26-28.

7. Yin Shidong, Chen Jing. The Value Implications and Practical Paths of Curriculum of Study Tour in Primary and Middle Schools [J]. Curriculum,Teaching Material and Method, 2018, 38(04), pp.116-120,115.

8. Wu Tao. Research on Socialist Core Values Education in Red Study Tour[J]. Journal of Hubei Polytechnic University (Humanities and Social Science), 2017, 34(02), P.32-34.

9. Yang Fei, Me Congmin. Reflections on the content of the educational experience of primary and middle school students' study tour from the perspective of developmental psychology [J]. Western China Quality Education, 2017, 3(17), pp.89-90.

10. Xu Mingbo. Moral Education Innovation and Realization Path of Study Tour [J]. The Teaching of Thought and Political Study, 2019, 4(4):8-12.

11. Stevens,J. Applied Multivariate Statistics for the Social Science(4th Ed.)[M].Mahwah, NJ: Lawrence Erllbaum, 2002, (7), pp.78. 